\title{
Antimony Doped Tin Oxide Aerogels for Applications in Energy Conversion and Energy Storage
}

\author{
J.-P. Correa-Baena ${ }^{1}$, Vahid Rastegar ${ }^{2}$, Paul G. Kotula ${ }^{3}$, Alexander G. Agrios ${ }^{1}$ and C. Barry Carter $^{2,4}$ \\ 1. Dept of Civil \& Environmental Engineering, University of Connecticut, 261 Glenbrook Rd, Storrs, \\ CT, 06269 \\ 2. Dept of Materials Science \& Engineering, U. of Connecticut, 191 Auditorium Rd, Storrs, CT \\ 06269-3222 \\ 3. Sandia National Laboratory, Materials Characterization Dept, POB 5800,MS 0886, Albuquerque, NM \\ 87185 \\ 4. Dept of Chemical \& Biomolecular Engineering, U. of Connecticut, 191 Auditorium Rd, Storrs, CT \\ 06269-3222
}

Tin (IV) oxide is an important n-type semiconductor with a large band gap ( $\mathrm{E}_{\mathrm{g}}=3.6 \mathrm{eV}$ at $\left.300 \mathrm{~K}\right)$. As a promising functional semiconductor material, $\mathrm{SnO}_{2}$ has stimulated considerable research interest for its potential application in various fields such as gas sensors [1], Li ion batteries [2], solar cells [3] and photocatalysis. $\mathrm{SnO}_{2}$ powders are frequently modified with dopant elements such as $\mathrm{In}, \mathrm{Sb}$ and $\mathrm{F}$ to give transparent-conductive oxides (TCOs) with high optical transmittance in the visible range, low electrical resistivity and good stability [4,5]. The stoichiometry, along with the nature, quantity and microstructural distribution of dopants plays an important role in determining the electrical and optical properties of $\mathrm{SnO}_{2}$ [5,6]. In this study, antimony-doped tin oxide (ATO) in aerogel form were synthesized with different $\mathrm{Sb}$ content $(5,10$ and 15\%) by a sol-gel process. Because of the small difference in ionic radius and electronegativity between $\mathrm{Sn}^{4+}$ and $\mathrm{Sb}^{5+}(10.8 \%$ and $5.6 \%$ difference, respectively) the replacement of the $\mathrm{Sn}^{4+}$ ions by $\mathrm{Sb}^{5+}$ can be done easily [7].

The morphology and structure of the ATO aerogels were characterized using field-emission scanning electron microscopy (FESEM) and transmission electron microscopy (TEM). To produce TEM specimens, the ATO aerogels were dispersed in ethanol using a sonicator; a single drop of this suspension was placed on a $3 \mathrm{~mm}$ copper TEM grid with a thin layer of amorphous carbon. When the grid had fully dried, the ATO aerogels were analyzed by SEM. X-ray energy dispersive spectroscopy (XEDS) confirmed that their chemical composition was unaltered. TEM analysis revealed that the dopant concentration had a profound effect on the physical properties of the particles. It was found that the increase in the $\mathrm{Sb}$ concentration corresponded to a decrease in particle size from $10-15 \mathrm{~nm}$ for undoped $\mathrm{SnO}_{2}$ to $3-10 \mathrm{~nm}$ for 15\% ATO. The increase in Sb content also caused a lattice contraction. This effect is presumably related to the lower ionic radius and higher oxidation state of $\mathrm{Sb}^{5+}$. The introduction of the antimony dopant may also produce additional adsorption sites on the surface of $\mathrm{SnO}_{2}$ particles, impeding particle growth and resulting in a significant increase of the specific surface area [8,9].

The importance and limitations of the characterization of this and similar materials will be discussed.

\section{References:}

[1] A. Sharma, M. Tomar, V. Gupta, J. Mater. Chem. 22 (44) 23608-23616, 2012.

[2] C. Xu, J. Sun, L. Gao, J. Mater. Chem. 22(3) 975-979, 2012.

[3] Z. Li, Y. Zhou, T. Yu, J. Liu, Z. Zou, Cryst. Eng. Comm. 14(20) 6462-6468, 2012.

[4] C. Terrier, J.P. Chatelon, R. Berjoan, J.A. Roger, Thin Solid Films 263(1), 37-41, 1995.

[5] B. Thangaraju, Thin Solid Films 402 (1-2), 71-78, 2002.

[6] C.B. Carter and M.G. Norton, Ceramic Materials: Science and Engineering, $2^{\text {nd }}$ Ed Springer NY, 2013

[7] J. Tamaki, T. Maekawa, N. Miura, N. Yamazoe, Sensors and Actuators B9, 197-203, (1992). 
[8] T. R. Giraldi, M. T. Escote, A. P. Maciel, E. Longo, E. R. Leite, and J. A. Varela, Thin Solid Films 515(4), 2678-2685, 2006.

[9] S. S. Lekshmy, G. P. Daniel, K. Joy, Appl. Surf. Sci. 274, 95-100, 2013.

[10] JPCB and AGA were funded by the National Science Foundation, Grant No. CBET-1332022. VR would like to acknowledge GAANN Fellowship from the Department of Education. This work was performed at Sandia National Laboratory in CINT, the Center for Integrated Nanotechnology, and in the Materials Characterization Department. Sandia is a multiprogram laboratory operated by Sandia Corporation, a Lockheed Martin Company, for the US Department of Energy under contract DEAC04-94AL85000.

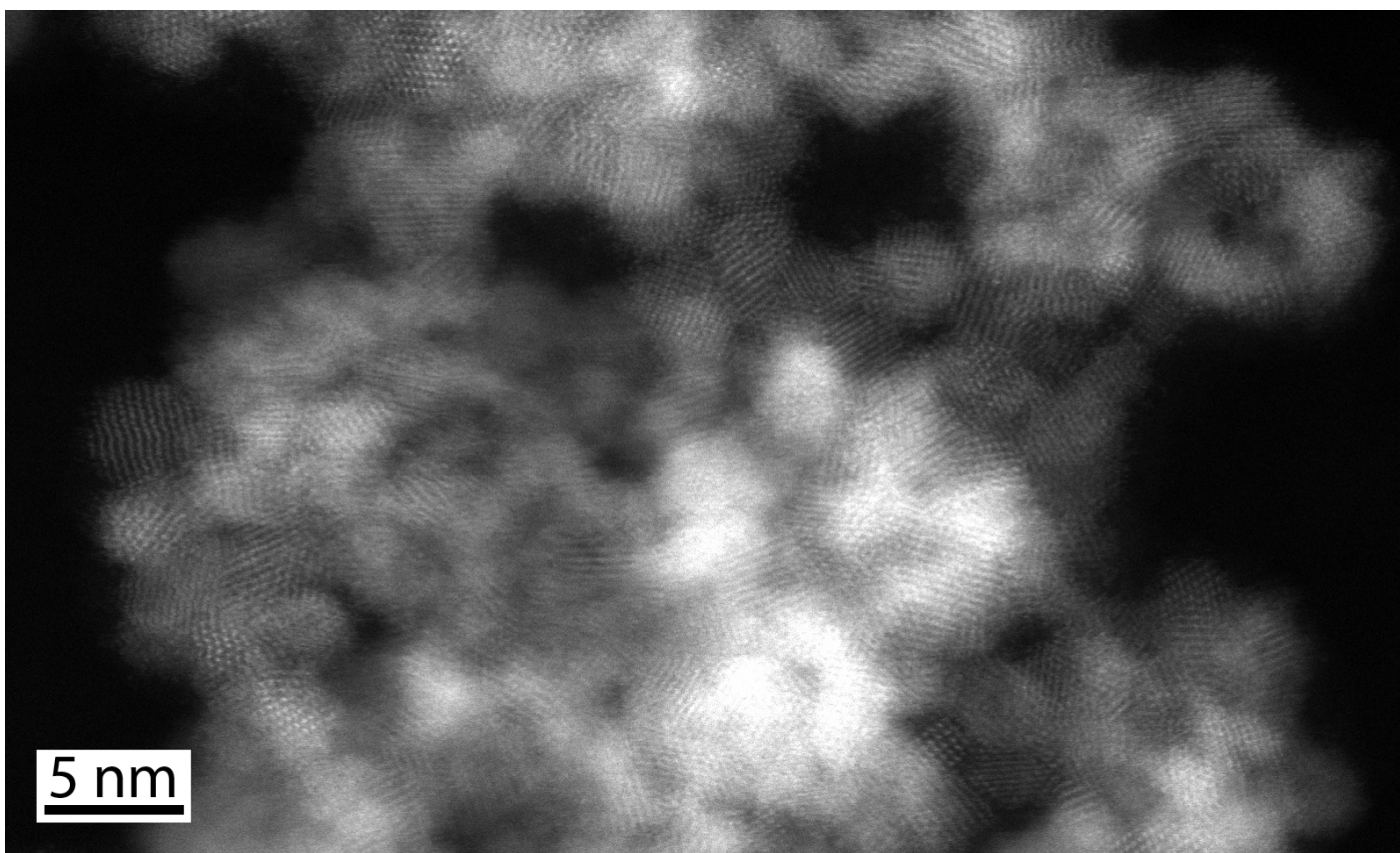

Figure 1. STEM image of $15 \%$ ATO showing the size of the particles and their crystallinity.
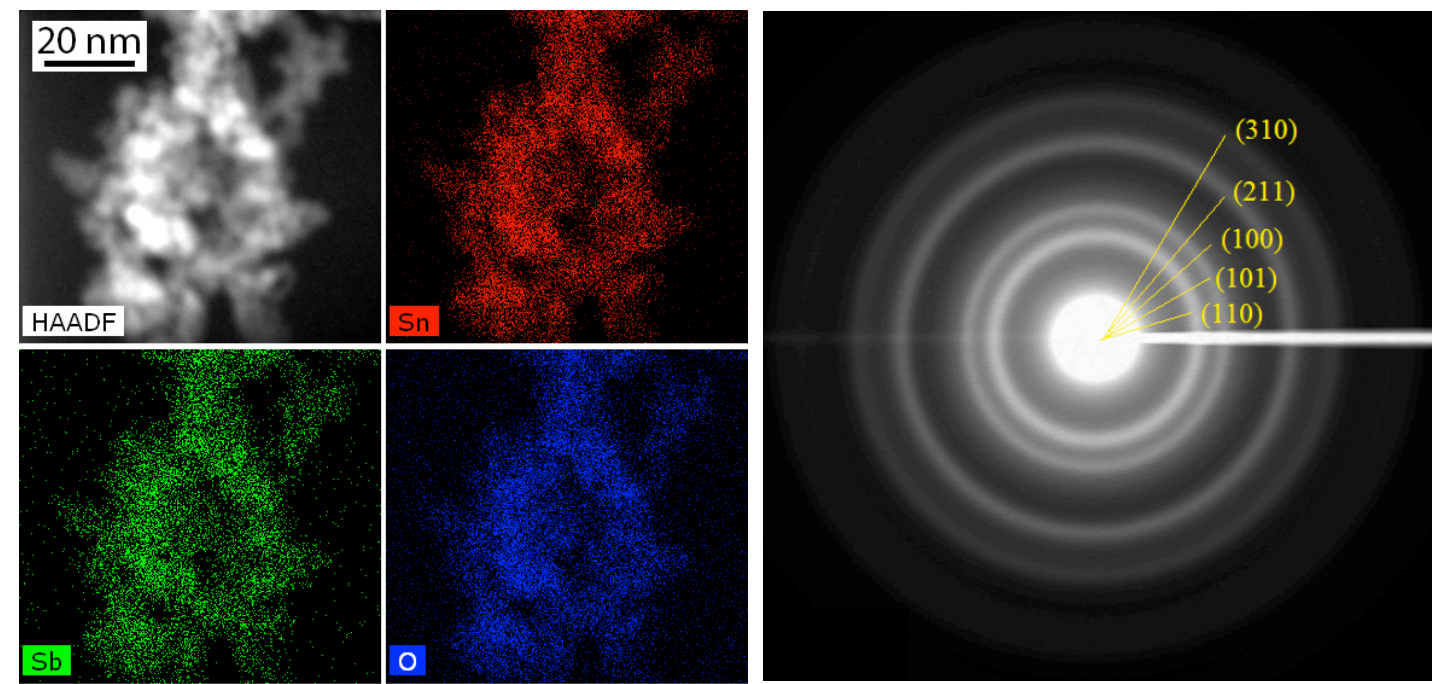

Figure 2. (Left) TEM Set of Titan Chemi-STEM images showing that the $\mathrm{Sn}, \mathrm{Sb}$ and $\mathrm{O}$ are all co-located.

Figure 3. (Right) The selected-area diffraction pattern confirming that the oxides has the rutile (tetragonal) crystal structure, consistent with $\mathrm{d}_{(110)}=3.41 \AA, \mathrm{d}_{(101)}=2.65 \AA, \mathrm{d}_{200}=2.33 \AA, \mathrm{d}_{(211)}=1.8 \AA$, $\mathrm{d}_{(310)}=1.45 \AA$. 